\title{
An unusual bladder mass: Dermoid cyst and review of the literature
}

\author{
Abdullah Gül ${ }^{1 *}$, Ahmet Sahan ${ }^{1}$, Canan Fırat ${ }^{2}$, Yılören Tanıdır ${ }^{3}$ \\ ${ }^{1} V$ an Education and Research Hospital, Department of Urology, Van, Turkey \\ ${ }^{2} V$ an Education and Research Hospital, Department of Pathology, Van, Turkey \\ ${ }^{3}$ Marmara University, School of Medicine, Department of Urology, Istanbul, Turkey
}

\begin{abstract}
Dermoid cysts are developmental benign anomalies and comprise at least two germ layer tissue. Dermoid cyst is usually known to be of primordial germ cell origin; however, there are some rare cases in which they have been noticed in other midline and paraxial organs. Although they generally settle in ovaries, they might be found in other tissues such as urinary bladder. Dermoid cyst should be kept in mind as a differential diagnosis for unusual presentation and histopathological appearances in bladder mass and should also be known that there is no need for further following up. We report a case of a 47-year-old woman with bladder dermoid cyst being the first case report from Turkey as a bladder mass resected endoscopically.
\end{abstract}

Key Words: Bladder mass, dermoid cyst, mature cystic teratoma of urinary bladder

\section{Introduction}

Dermoid cysts originating from primordial germ cell are considered benign neoplasms. They are very rarely seen in urinary bladder, commonly occur in ovaries. Up to date there are only 9 cases published in English literature. We present here a 47 year-old female with primary bladder dermoid cyst which is the first case report from Turkey as a bladder mass resected endoscopically.

\section{Case report}

A 47 year-old female patient presented with painless macroscopic hematuria. Ultrasound scan revealed a single echogenic solid bladder mass in approximately $1 \times 1 \mathrm{~cm}$ in size within the lumen of the urinary bladder. The lesion was reported to be located at the posterior wall of the bladder with normal upper urinary tract. Physical examination, serum biochemistry were normal while urine analysis revealed $25 \mathrm{RBC} / \mathrm{microl}$. She had no other complaints bowel and genitourinary tract. Cystoscopy showed a single $1 \mathrm{x} 1 \mathrm{~cm}$ solid mass protruting from a small diverticula at the posterior urinary bladder wall. The rest of the bladder mucosa seemed to be normal. A complete transurethral resection (TUR) was performed and both the tumor and the tumor base were sampled individually for histopathologic examination. The histopathologic specimen analysis revealed a total of 6 TUR chips with the greatest chip dimension being measured as $5 \times 2 \times 1 \mathrm{~mm}$. All chips' color was greyish white. Microscopic examination shown multiple skin tissues lined by stratified squamous epithelium with no urothelial epithelium. Each specimen section contained skin appendages, such as hair follicles and sebaceous glands (Fig. 1a-b). One specimen section contained a cyst that very closely resembled an epidermal (infundibular) cyst (Fig. 2a-b). The final histopathological diagnosis was reported as dermoid cyst. After this histopathological diagnosis we performed magnetic resonance imaging for evaluating the pelvis whether this was primary bladder dermoid or secondary to bladder wall invasion of primary ovarian dermoid. MRI revealed normal pelvis consisting of no cyst.

\section{Discussion}

Mature cystic teratoma, also called as dermoid cyst, is the most common benign ovarian germ cell tumor (1). Dermoid cysts consist of one or more types of cell originating from 3 germ layers (2). Histologically, they may contain mature or immature tissues and occasionally malignant elements. They commonly occur beside the areas 

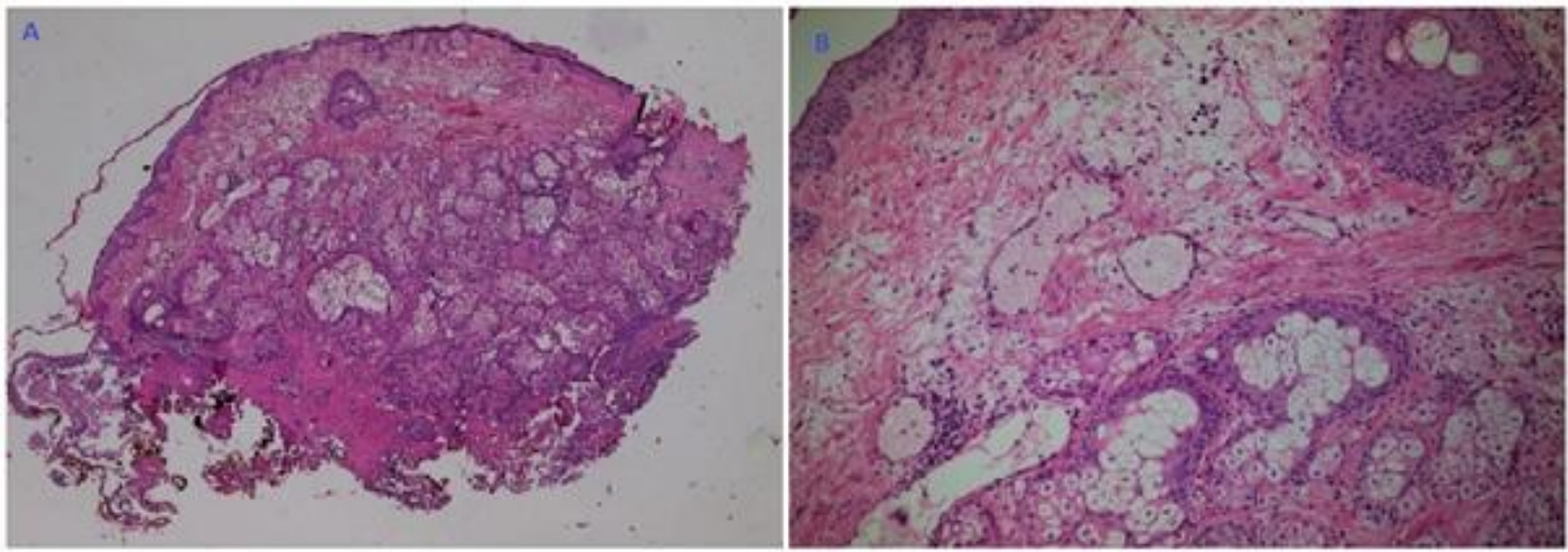

Fig. 1. (A) Photomicrograph demonstrates stratified squamous epithelium and pilosebaceous units (H\&E, Original magnification $\mathrm{x} 40$ ). (B) High-power view of the hair follicle (right top) and sebaceous glands (bottom) (H\&E, Original magnification $\mathrm{x} 200)$.
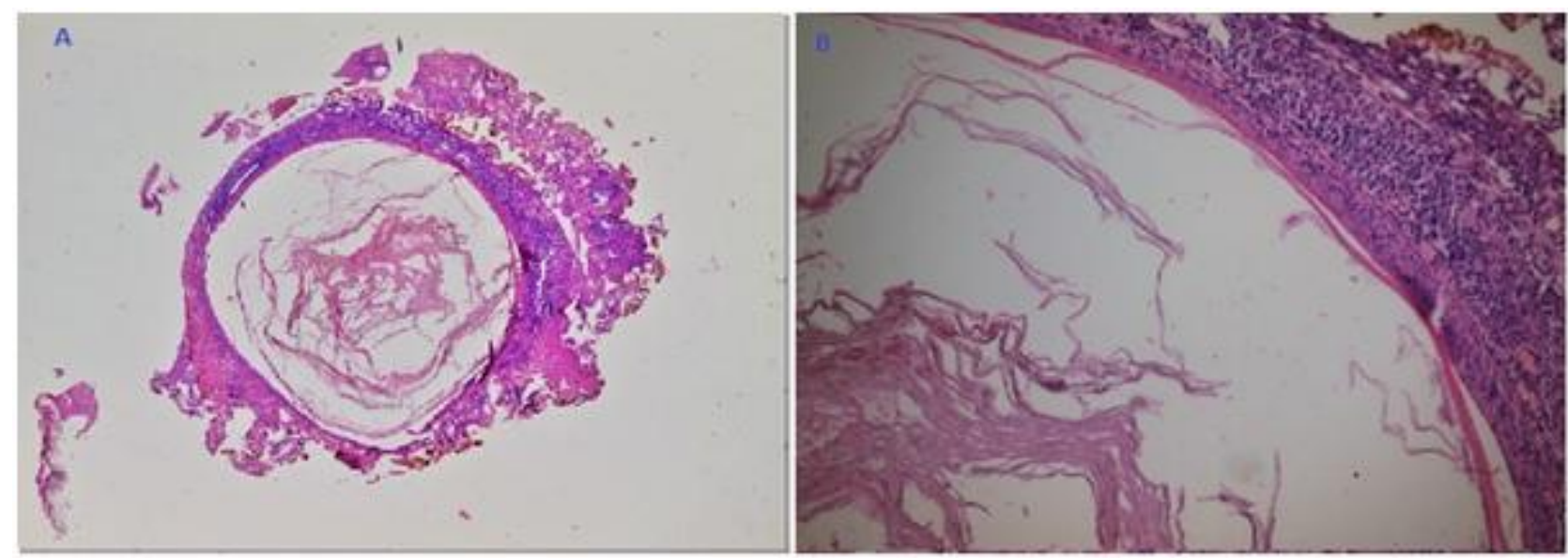

Fig. 2. (A) Image of epidermal (infundibular) cyst whose lumen is keratin-filled (H\&E, Original magnification $\mathrm{x} 40$ ). (B) On the left side, lamellated keratin can be seen, on the right side flattened squamous epithelium is distinguished (H\&E, Original magnify.

of embryogenic fusion lines, in midline and paraxial organs (3). Dermoid cysts are rather rarely encountered in the urinary bladder. So far only 11 cases of dermoid cysts were reported to be seen within the urinary bladder (4-14). However, only 9 of them were in English literature (4-6, 8, 9, 1114). Each of these patients was presented with lower urinary tract symptoms. Two of them were evaluated with cystoscopy. In one of these two cases, cystoscopic appearance was like a teratoma since hair follicle could easily be seen while in the other case it was like a bladder mass $(4,11)$. In our case, the chief complaint was macroscopic hematuria without voiding and storage symptoms of the bladder. Cystoscopic appearance was like a solid bladder mass originating from bladder diverticula. The histopathological findings have been confusing for pathologist because of the extremely rare bladder mass. This case is important in terms of differential diagnosis of bladder mass with unknown origin. Bladder dermoid cyst should be reminded as an unusual bladder mass and the patients can be reassured that it is benign and there is no need for further following up (9).

Acknowledgement: We would like to thank the staff of Van Education and Research Hospital, especially to those in the urology clinic, in the pathology clinic and in the operation theater, for their generous contributions and assistance.

\section{References}

1. Ayhan A, Bukulmez O, Genc C, Karamursel BS, Ayhan A. Mature cystic teratomas of the ovary: case series from one institution over 34 years. European journal of obstetrics, gynecology, and reproductive biology 2000; 88: 153-157. 
2. Hackethal A, Brueggmann D, Bohlmann MK, Franke FE, Tinneberg HR, Munstedt K. Squamous-cell carcinoma in mature cystic teratoma of the ovary: systematic review and analysis of published data. The Lancet Oncology 2008; 9: 1173-1180.

3. Pradhan P, Thapa M. Dermoid Cyst and its bizarre presentation. JNMA; journal of the Nepal Medical Association 2014; 52: 837-844.

4. Agrawal S, Khurana N, Mandhani A, Agrawal V, Jain M. Primary bladder dermoid: a case report and review of the literature. Urologia internationalis 2006; 77 : 279-280.

5. Jain SK, Kaza RC, Vindal A, Bains L. Vesical dermoid: an unusual presentation. International journal of urology : official journal of the Japanese Urological Association 2010; 17: 824-825.

6. Kuyumcuoglu U, Kale A. Unusual presentation of a dermoid cyst that derived from the bladder dome presenting as subserosal leiomyoma uteri. Clinical and experimental obstetrics \& gynecology 2008; 35: 309310.

7. Valizadeh A, Arend P, Diallo B, Kotowitz A, Pontus T. Dermoid cyst of the bladder: Case report. Acta urologica Belgica 1991; 59: 79-83.
8. Lidzki A. Dermoid Cyst of the Bladder: Case Report. Annals of surgery 1939; 109: 274-276.

9. Okeke LI, Ogun GO, Etukakpan BR, Iyama A, Adeoye AO, Duduyemi BM. Dermoid cyst of the urinary bladder as a differential diagnosis of bladder calculus: a case report. Journal of medical case reports 2007; 1: 32.

10. Agbreta N, Boutens A, Debodinance P. Dermoid cyst of the urachus: a case report and review of the literature. Journal de gynecologie, obstetrique et biologie de la reproduction 2006; 35: 75-78.

11. Misra S, Agarwal PK, Tandon RK, Wakhlu AK, Misra NC. Bladder teratoma: a case report and review of literature. Indian journal of cancer 1997; 34: 20-21.

12. Bhalla S, Masih K, Rana RS. Teratomas of rare sites: a review of ten cases. Journal of the Indian Medical Association 1991; 89: 291-294.

13. Sabnis RB, Bradoo AM, Desai RM, Bhatt RM, Randive NU. Primary benign vesical teratoma. A case report. Archivos espanoles de urologia 1993; 46: 444 445.

14. Bhuiyan ZH, Akhter N, Islam MF, Khan SA, Tawhid MH. Pilimiction. Mymensingh medical journal : MMJ 2008; 17: 107-110. 